\title{
A fortaleza e o navio: espaços de reclusão na Carreira da Índia
}

\author{
Andréa Doré
}

Nas crônicas e nos estudos sobre a expansão portuguesa são numerosas as referências à intimidade dos portugueses com o mar em contraste com certa estranheza ao lidar com a territorialidade. O navio era um prolongamento do território português, representava o reino em qualquer mar por onde andasse. Não foi por outra razão que Vasco da Gama, em sua segunda viagem à Índia, optou por não sair do navio para encontrar as autoridades locais ou Pedro Álvares Cabral, ao chegar a Calicut, exigiu cinco fidalgos como reféns em sua nau para desembarcar, entre inúmeros outros exemplos. ${ }^{1}$ A nau, terreno sagrado para os portugueses, jamais seria desarmada, afirma Sérgio Buarque de Holanda, como fizera Cortés ao chegar à Nova Espanha para aproveitar o lenho nas construções de terra firme. Ele salienta a facilidade das comunicaçôes por via marítima ou fluvial - menosprezada pelos castelhanos - como "o fundamento do esforço colonizador de Portugal". ${ }^{2}$

Os registros existentes são reveladores neste sentido. A inscrição deixada nos rochedos de Ielala, a 150 quilômetros da foz do Zaire, atingidos por Diogo Cão em 1483 ao penetrar no território até onde o volume das águas permitiu, sentencia: "Aqui chegaram os navios do esclarecido Rei Dom João o segundo de Portugal." ${ }^{3}$ Não foi preciso aos portugueses descer da nau para travar os primeiros contatos com o reino do Congo e ali ter uma experiência de missionação que não se repetiu, seja na África seja na Ásia.

Mesmo que, como salienta Pearson, não se deva ver os portugueses como "intrépidos marinheiros", ${ }^{4}$ quando se trata do Oriente, no mar estava a vantagem dos portugueses e só por mar eles podiam controlar e tributar o comércio. ${ }^{5}$ Essa avaliação já circulava na Europa no início do Quinhentos quando Leonardo Ca’ Masser escreveu de Lisboa em 1506 para informar à República de Veneza que os portugueses dominavam os mares do Oriente sem real oposição. ${ }^{6}$ Anos mais tarde, Afonso de Albuquerque descrevia 
ao rei D. Manuel de que forma a tomada de Goa mudaria a visão que até então os "mouros" tinham dos portugueses. Ele afirmava que a resistência dos indianos em negociar ocorria por verem os portugueses

mui desapegados na Índia e que não fazíamos fundamento da terra, [...] porque até agora não viram eles assento na Índia a que tivessem acatamento, senão a Goa, nem nos houveram por vizinhos e moradores perpétuos na Índia [e nos tem] como homens que esperávamos de a deixar cedo. ${ }^{7}$

Albuquerque, ao defender que o sucesso da empresa portuguesa na Índia dependia da fixação de bases sólidas em terra, enfrentava uma forte corrente em Portugal adepta de um "império flutuante", ${ }^{8}$ vincado na exploração marítima somente. Esse desapego foi defendido por outros homens da Coroa. Conforme verificou Russell-Wood, numa carta escrita em Goa, provavelmente em 1539, D. João de Castro enfatizava que

em nenhuma maneira os Portugueses deviam adentrar um só palmo pela terra dentro da Índia, porque nenhuma outra coisa sustenta a paz e conserva em amizade os Reis e Senhores da Índia, senão crerem e terem por muito averiguado que somente nos contentamos do mar, e que nenhum propósito nem imaginação reina em nós de lhe cobiçarmos suas terras. ${ }^{9}$

A mesma preocupação registrou-se em relação ao Brasil. O primeiro governador-geral, Tomé de Sousa, trazia em seu regimento proibição expressa de trato terra firme adentro sem licença especial do governador ou do provedor-mor da fazenda real. Assim como ocorreu na Índia, não se podia ir "de huas capitanias para outras por terra sem licença dos ditos capitães ou provedores posto que seja por terras que estãm em paz para evitar alguns enconvenientes". ${ }^{10}$ Sérgio Buarque de Holanda, ao tratar desse período, conclui que a nau, terreno sagrado para os portugueses, jamais seria desarmada, como fizera Cortez ao chegar à Nova Espanha para aproveitar o lenho nas construções de terra firme. ${ }^{11}$ Ele salienta a facilidade das comunicações por via marítima ou fluvial - menosprezada pelos castelhanos - como "o fundamento do esforço colonizador de Portugal". ${ }^{12}$ Frei Vicente de Salvador - o primeiro historiador do Brasil - poderia também ter escrito sobre a Índia, e com mais razão, sua clássica afirmação a respeito dos portugueses no Brasil que, até o século XVII, viveram "arranhando as costas como caranguejos". ${ }^{13}$ As especificidades dos continentes americano e asiático 
parecem ter só mais tarde alterado a postura dos portugueses. Se Frei Vicente exagerava em 1627, já que os portugueses naquele momento avançavam para o interior, Sérgio Buarque também atribui ao Brasil o que, na realidade, ocorreu na Índia. Ele afirma que "mesmo em seus melhores momentos, a obra realizada no Brasil [e nós diríamos, na Ásia] pelos portugueses teve um caráter mais acentuado de feitorização do que de colonização". ${ }^{14}$

Uma vez no mar, o navio, e na falta deste, o litoral, era então o espaço de eleição. As fontes da época explicitam essa oposição mar e terra. O florentino Andrea Corsali, que viajou para a Índia na frota de Lopo Soares de Albergaria, vice-rei que sucedeu Afonso de Albuquerque, foi bastante objetivo na sua observação dos portugueses. Ele escreveu ao duque Juliano de Medici dizendo que pretendia ficar um certo tempo por aquelas terras para "percorrer o interior da terra firme e comparar os nomes antigos que deu Ptolomeu às localidades com os modernos que hoje estão". O que ele então sabia era de forma imprecisa, já que "estes Portugueses não se ocupam de entender das coisas da terra firme, porque seu lucro está no mar e não na terra." 15

Lopo de Sousa Coutinho, testemunha ocular do cerco sofrido pelos portugueses em Diu em 1538, comentou a falta de prática dos portugueses em atacar e derrubar muralhas. O Governador ao ir para Diu ordenou de que forma seria a batalha, "a qual havia de ser por mar [...] porque até este tempo nunca em a Índia os nossos tinham batido muro: \& eram tão pouco destros nisso." ${ }^{\prime 16}$ Os textos produzidos por italianos que viajaram para a Índia ao longo do século XVI confirmam que os portugueses estiveram presentes em todas as importantes cidades da costa indiana. Podese dizer igualmente que os portugueses só estiveram presentes nas cidades mais importantes da costa. Cochim, no Malabar, e Chaul, Baçaim e Damão, no Guzerate representariam, mais tarde, além de Goa, iniciativas de ampliação do território de domínio. Essa concentração no litoral chegou a valer aos portugueses o apelido de "battiplajas, que quer dizer varrepraia”, atribuído, segundo Filippo Sassetti, por um negro ao se referir ao fato dos portugueses não entrarem um palmo terra adentro. ${ }^{17}$

Os portugueses exerceram então a "perspectiva do navegador", como diz João Rocha Pinto, em detrimento do olhar do caravaneiro. A cultura portuguesa estruturou-se, assim, como "uma cultura que olha do mar, 
com um horizonte visual proporcionado pela amurada ou pela gávea de uma nau" ${ }^{18}$ Olhava do mar, segundo Luciana Picchio, porque era onde eles se sentiam superiores. Ao analisar as diferentes visões de portugueses e italianos diante da expansão, Picchio afirma que "a especial atenção às águas dos portugueses [...] pode dever-se ao fato de viverem numa risca de terra à beira do Atlântico e como que esmagados pela Espanha e pela Europa, e só se sentirem em pé de igualdade ou até de superioridade no Oceano". Dessa forma os portugueses "sofrem de mal de terra. As terras incutem mais medo, com seus cafres e suas costas de penhascos, do que as águas com as suas fúrias e os seus corsários". ${ }^{19}$

Partindo da familiaridade com o litoral manifestada pelos portugueses, algumas relações podem ser feitas entre o navio - espaço de reclusão privilegiado pelos portugueses - e a fortaleza - igualmente um espaço de reclusão, funcionando como um enclave em terra firme, no litoral. Este paralelo refere-se à presença portuguesa no Oriente onde, como se pode verificar, as fortalezas funcionaram como uma instituição fundamental da expansão. Mesmo com uma função diferente, mais de defesa do que de controle, no Brasil também foi construído um grande número de fortes e fortalezas em todo o território, do Amapá ao Rio Grande do Sul. Um estudo feito por Anibal Barreto fala de "cinturão de fortalezas" no período colonial e conta, apenas na Baía de Todos os Santos, o ponto mais defendido do Brasil, um total de 25 edificaçōes, entre fortalezas, fortes, redutos e fortins. ${ }^{20}$

No caso do Oriente, a construção de fortalezas esteve entre os primeiros objetivos definidos pelos portugueses ao chegar ao oceano Índico. O poder sobre praças fortificadas, estabelecidas ao longo da costa, com raras vocações para uma urbanização mais ampla, representou um modelo de dominação cercada, não no sentido apenas militar, mas no de sua estrutura econômica e social. A vivência desse cerco, nem sempre declarado, se estendeu por todo o século XVI e as primeiras décadas do século XVII, quando potências européias, interessadas tanto na circulação de mercadorias quando na sua produção - ingleses e holandeses - conquistaram a maior parte dos enclaves portugueses. Do ponto de vista militar, a situação de cerco é mais evidente e ocorreu em vários momentos, de modo mais ou menos dramático, nem sempre ricamente documentado, por vezes sendo-o de forma eloqüente. 
A construção de fortalezas integrava o próprio discurso de dominação elaborado pela Coroa de Portugal, como se verifica pela afirmação de D. Manuel, ao nomear o vice-rei D. Francisco de Almeida: "Vos dou o título de Visorey, tanto que fizerdes a primeyra fortaleza do Cabo da Boa Esperança para dentro." ${ }^{21} \mathrm{Na}$ armada composta de oito naus grossas para carga, seis navetas pequenas e seis caravelas latinas, seguiam quatro capitães já nomeados para futuras fortalezas: Cochim, Cananor, Quíloa e Angediva, além de madeira lavrada - portas e janelas -, para as futuras edificações. ${ }^{22}$

O Regimento entregue pelo rei a D. Francisco de Almeida confirmava os planos reais e nele indentifica-se que o objetivo geral era afastar os turcos e controlar os árabes, não dispensando ainda um recado aos venezianos:

E porque nos parece que nenhuma cousa poderia mais importar a nosso serviço que termos uma fortaleza na boca do Mar Roxo (...) porquanto por aqui se cerrava não poderem mais passar nenhuma especiaria à terra do Sultão, e todos os da Índia perderem a fantasia de mais poderem tratar senão connosco. ${ }^{23}$

No ano seguinte, em 1506, D. Manuel escreveu ao vice-rei ordenando a construção de uma fortaleza em Socotorá e determinando que fosse em pessoa a Malaca negociar a construção de uma outra, com o consentimento ou não da gente do país. ${ }^{24}$ Naquele mesmo ano, Tristão da Cunha, conforme conta o informante da República de Veneza em Lisboa, Leonardo Ca' Masser, "levou consigo uma fortaleza de lenho para assentá-la em uma ilha que se chama Curitoras [Socotorá], que está na boca do Mar Vermelho, onde se diz ser o ponto principal; e uma vez defendido, estarão totalmente bloqueadas as especiarias para a Meca e a Síria”. ${ }^{25}$ Esta fortaleza chegou a ser construída, em 1507, mas mostrou-se ineficaz no combate à navegação muçulmana e foi abandonada em 1512 .

Para suceder D. Francisco de Almeida, foi nomeado governador Afonso de Albuquerque com o projeto de adquirir um grande número de pontos fortificados. Em 1510 decidiu tomar Goa, aconselhado pelo corsário-mercador Timoja, em 1513 cercou Adém e fracassou, no ano seguinte retomou o controle de Ormuz e tomou em conjunto Sofala, Cochim, Socotorá e Malaca. Podemos assim considerar Afonso de Albuquerque como o principal empreendedor da política das fortalezas no Índico, criador de uma "cadeia militarizada". ${ }^{26}$ que se estendia do Ceilão à África Oriental. 
Sobre essas duas instituições-chave da expansão-portuguesa - a fortaleza e o navio - debruçara-se, já em finais do século XV, o espírito renascentista que buscava nos gregos a confirmação de suas especulações e no engenho humano a resposta para enfrentar as carências dos homens e a fúria dos elementos. Nesse caso devemos falar de arte da fortificação e da arte náutica ou da navegação. ${ }^{27}$ A primeira se expandiu pela Europa a partir da Itália e encontrou na península Ibérica expressões e cronologia particulares, podendo a sua vulgarização ser incluída entre os fatores que propiciaram a construção de fortalezas em toda a extensão das navegações portuguesas. Tratados e manuais da arte de fortificar proliferaram no período, chegando a Portugal não só os textos como os mestres. ${ }^{28}$

A construção de barcas, naus, urcas, galeões e caravelas recebeu dos portugueses não só o aprimoramento e adaptações aos usos e aos mares como o espírito científico da época. A arquitetura naval portuguesa teve como figura pioneira Fernando Oliveira, autor do Livro da fábrica das naus, publicado apenas em 1898 por Henrique Lopes de Mendonça ${ }^{29}$ e Ars nautica, cujo manuscrito foi localizado e editado por Luís de Matos em 1960. ${ }^{30}$ É também de sua autoria a Arte da Guerra do Mar, publicado ainda em 1555 em Coimbra. Nascido em 1507 de família modesta, Oliveira foi educado pelos dominicanos, mas avesso à rigidez da autoridade religiosa refugiou-se em Castela aos 25 anos. Nos finais dos anos 1530 entrou em contato com a corte de Henrique VIII da Inglaterra, depois que os ingleses o capturaram a bordo de uma nau francesa que havia participado da infeliz tentativa de invadir a Ilha. Seduzido pelas reformas do soberano, Oliveira retornou a Portugal, acusado de professar idéias heréticas e no ano de 1547, já estabelecida a Inquisição, foi processado e considerado culpado. Essa sentença definitiva o levou a abjurar oficialmente em setembro de 1548, tendo passado ainda dois anos nos cárceres do Santo Ofício e um no monastério de Belém antes de obter o perdão. Oliveira foi outras vezes importunado pela Inquisição, até que em 1565 tem-se notícia de uma pensão anual de $20 \$ 000$ réis concedida a ele pelo rei D. Sebastião. Dedicou-se então às suas duas principais obras náuticas, que não viriam a público enquanto durasse o Tribunal do Santo Ofício. ${ }^{31}$

O Livro da fábrica das naus não se preocupa, como o nome diz, com a arquitetura em relação ao comportamento dos homens. $\mathrm{O}$ objetivo do 
autor era trazer à luz, pela primeira vez, a disciplina da "arte da navegação", "da qual ninguem escreueo attegora, em nossa lingua, nem greca, nem latina, nem outra algua que eu sayba”, ${ }^{32}$ definindo regras de construção que atendessem à diversidade de funçôes de patrulha ou de carga das embarcaçõos e dos produtos comercializados pelo reino - pau-brasil, açúcar, metais, corantes, tecidos, tabaco e especiarias.

$\mathrm{Na}$ arte da fortificação, como afirma Mathias Dagen, a natureza serve de modelo para o homem; ela é mestre em fortificar, usando tanto a terra como o mar. A arte, ao imitar a natureza, substitui as montanhas por bastiôes e a água - os rios ou o mar -, por fossos. ${ }^{33}$ Da mesma forma, Fernando Oliveira, no sétimo capítulo de seu livro, pretende mostrar como os homens devem imitar a natureza no fabrico das naus. A arquitetura naval devia fazer das formas dos peixes seus elementos de trabalho: remos, timões e velas teriam sua origem na imitação dos órgãos desses animais. ${ }^{34}$

Num primeiro momento, e para grande parte das fortificaçôes, seria mais correto falar de castelo e não de fortaleza, o que ainda mais aproxima as fortalezas e os navios. Estes, sendo, no momento da chegada dos portugueses à Índia, semelhantes aos castelos medievais, condizentes com a tradição da fidalguia portuguesa, mais interessada na luta à espada, por ser essa considerada digna e nobre, do que na guerra com base na artilharia. Durante o século XV, os navios funcionavam como "castelos navais móveis", seja no aspecto funcional, seja pela semelhança entre ambos, "em especial com as naus em que as peças eram dispostas ou por cima da amurada ou em janelas redondas ou quadradas, rasgadas no corpo do navio, tal como nas fortalezas em terra, e apresentavam à popa e à proa dois alterosos castelos com sucessivos níveis de canhoeiras". ${ }^{35}$

O Infante D. Henrique teria sido o primeiro a incluir peças de artilharia a bordo das caravelas, mas sem resultado. D. João II, em seguida, construiu peças de bronze para equipar os navios, resolvendo o problema do desequilíbrio, instalando-as numa coberta a um nível inferior ao convés e no corpo dos navios. Nas fortalezas fez-se o contrário: as conhoeiras começaram a um nível inferior e logo passaram para um posicionamento mais alto, entre merlóes. ${ }^{36}$ Rafael Moreira compara:

Se o tiro rasante à flor da água em ricochete experimentado por D. João II transformou as caravelas e naus em fortalezas flutuantes, o cruzar de fogos 
que fazia manter a distância os exércitos de potências hostis tornou os primeiros entrepostos fortificados em autênticas naves ancoradas em pedra. ${ }^{37}$

Invenções gêmeas do período das descobertas aproximam fortaleza e navio do ponto de vista técnico e foram responsáveis, na avaliação de Moreira, pelo sucesso obtido pelos portugueses no percurso de rotas marítimas inéditas assim como na manutenção de domínios terrestres tão pontuais e isolados. A primeira invenção diz respeito às fortificaçōes. A chamada "frente abaluartada" reunia dois ou mais baluartes de forma a permitir uma defesa mútua do terreno e que, no seu início, era uma plataforma angular saliente ao muro, com espaço suficiente para a instalação e manobra das peças de fogo. A outra invenção foi a caravela, desenvolvida ao longo do século XV e cuja forma seria fixada, após as viagens de Cristóvão Colombo e Vasco da Gama, na "caravela de armada", com velas latinas e quadradas. ${ }^{38}$ Baluarte e caravela nasceram, segundo Moreira, de uma mesma necessidade: a de resistir a grandes pressões físicas contrárias. De um lado o ímpeto dos exércitos e, de outro, a força dos ventos. Enquanto o baluarte permitia o cruzar de fogos, a nova embarcação permitia a navegação à bolina, ou seja, navegar contra a direção dos ventos dominantes, assegurando o regresso nas viagens de reconhecimento ao longo da costa africana ou no mar alto. ${ }^{39}$

Quando falamos de navio e de fortaleza estamos falando de instituições essenciais da expansão portuguesa, mas que são, igualmente, instituições totais. O conceito de instituição total, estabelecido por Erving Goffman e utilizado por Maria Angélica Madeira em seus estudos sobre a sociedade no navio, pode ser aplicado também à fortaleza. Na definição de Goffman, "instituição total é um local de residência e trabalho, onde um grande número de indivíduos com situação semelhante, separados da sociedade mais ampla por considerável período de tempo, levam uma vida fechada e formalmente administrada”. ${ }^{40}$ A respeito do navio, escreve Madeira:

Como instituição, a singularidade do navio mercante reside no fato de ser um 'híbrido social' flutuante, sociedade constituída para a circunstância daquela viagem. Ponto de cruzamento de interesses, espaço de alta tensão, pela concentração de poder, pela ansiedade com a expectativa do enriquecimento. Tensão também criada pela situação de provisoriedade e instabilidade assim como pela presença de estruturas altamente hierarquizadas em um espaço afeto às misturas. ${ }^{41}$ 
Em relação às fortalezas portuguesas na Índia fala-se de unidades autônomas, organizadas de forma a oferecer o essencial a seus habitantes, cada uma delas identificada como uma periferia do reino com "claros contornos de espaço de fronteira" ${ }^{42}$ Essa autonomia, no entanto, não dispensava o contato entre elas, mesmo por questôes rotineiras, uma vez que o tempo de permanência dos homens nesses espaços não era sempre predeterminado; apenas os cargos mais elevados eram ocupados por um período fixo de três anos. Um exemplo dessa necessidade de comunicação, que não se fazia "senão por mar e com cáfilas", para atender a problemas do cotidiano, está na carta enviada pelo rei a D. Jerônimo de Azevedo. De Baçaim, no Guzerate, chegavam ao reino reclamaçôes das Misericórdias de que não podiam mais sustentar os presos que ficavam a seu cargo. Os despachos para a conclusão dos processos deveriam ser feitos pela Relação de Goa, para onde seguiam apenas uma ou duas vezes por ano, por causa das monções e dos cuidados necessários contra os corsários. ${ }^{43}$

A vida numa fortaleza, localizada em solo inimigo, pressupóe certo na conduta dos soldados, sérias medidas de segurança e, sobretudo, a distribuição de funções ao longo de uma rígida rotina. O que ocorria no Estado da Índia, por sua vez, era um esforço a partir da metrópole, e da burocracia sob sua tutela, de consolidar o espaço da fortaleza como uma unidade militar independente, capaz de garantir pelo controle do mar a manutenção do poder da coroa. Esse esforço, no entanto, não foi bem-sucedido, a se verificar o grande número de denúncias que chegavam a Lisboa de corrupção, abuso de poder, indisciplina e desmandos ocorridos na Índia. ${ }^{44}$ Não se pode, apesar disso, desconsiderar que a fortaleza, no momento em que sofria um cerco, obrigava à convivência indivíduos que, de outra maneira, estariam separados. Se poucos homens havia para proteger o Império Asiático, todos eram convocados quando surgia uma ameaça: fidalgos, soldados, marinheiros, comerciantes, casados, estrangeiros, servos e escravos. Quanto maior a liberalidade no momento de paz, maior também a contrariedade dos homens quando constrangidos a partilhar espaço, atividades e provisões.

Segundo Maria Angélica Madeira, no caso do navio a arquitetura estabelecia a hierarquia social, marcada pela posição e tamanho do espaço designado para cada membro ou grupo pertencente à tripulação, ${ }^{45}$ ou seja, o local de residência. ${ }^{46}$ As cabines assim se dividiam de forma que a 
maior fosse destinada ao capitão, quase sempre um nobre que representava os interesses da Coroa, seguida da cabine do mestre; as duas seguintes, um pouco menores, ao piloto e ao segundo piloto. Outras duas, ainda menores, cabiam ao escrivão e ao despenseiro. Outros quartos pequenos, localizados do lado da popa e a estibordo, eram destinados ao contramestre, ao guardião, aos carpinteiros e seus calafates, ao tanoeiro e aos marinheiros. Nos porões, além da pimenta e das pipas de água, vinho e vinagre, viajavam os escravos ou degredados; ${ }^{47}$ os grumetes ficavam debaixo dos castelos de proa, ou à descoberta. Sem um espaço especial, os soldados deveriam dormir no convés. ${ }^{48}$ É preciso acrescentar que na sociedade compreendida no navio conviviam homens das mais variadas origens, a tripulação sendo recrutada pelos portos da Ásia ou da África, sobretudo para as carreiras do comércio interasiático. Esse caráter cosmopolita não livrava o espaço do navio de tensões, ligadas sobretudo a questões religiosas. Geoffrey Scammell cita o caso de um intrépido missionário que, num navio português em viagem de Cochim a Bengala, em 1628, precipitouse, "com o crucifixo na mão nos 'alojamentos das mulheres mouras, as esposas dos marinheiros', para convertê-las enquanto ainda era tempo". ${ }^{49}$ Para os que embarcavam na Carreira da Índia, as dificuldades eram incontáveis e levaram Filippo Sassetti a escrever que

se muito se considerasse essa viagem antes de embarcar, e como se está sete meses a biscoito e água suja, num espaço pequeno em meio a oitocentos e novecentas pessoas, morto de fome, de sede, de penúria e maus-tratos, imagino que ninguém, ou bem poucos se meteriam a sequer a ver a Índia à custa de tanto sofrimento. ${ }^{50}$

Podemos lamentar que o exigente florentino não tenha freqüentado as fortalezas portuguesas, cujas informaçôes são bastante fragmentárias. A relativa oferta de espaço, no entanto, se comparada às restriçóes impostas num navio, permitia a construção de casas que abrigassem as famílias. A organização do espaço priorizava os edifícios, como as residências dos oficiais do rei, armazéns das mercadorias a serem comercializadas e de armas e munições e as instituições religiosas, cuja presença na paisagem era marcada pelas igrejas e conventos.

As plantas das fortificações indicam que a arquitetura normalmente obedecia às condições do terreno e do material disponível, mas não se 
mediam despesas, "fazia-se, mesmo, aquilo que os engenheiros italianos propunham nas gravuras dos seus tratados impressos, mas ninguém em Itália tinha a coragem - ou os meios - de construir". ${ }^{51}$ Afonso de Albuquerque, no entanto, ao defender seus projetos, reclamava que os navios tomavam o que caberia às fortalezas:

... metem-nos na armada com um pouco de arroz e uns poucos cocos, e cada um com suas armas, se as tem; nos vossos armazéns cá não há nenhuma cousa, um prego que se cá faz, assim como o tiram da forja, assim o vão logo pregar no costado da não. ${ }^{52}$

A atração que exercia o navio, a promessa de lucro na realização do comércio, para não suspeitarmos da própria mobilidade a ele relativa em comparação ao confinamento da fortaleza, foi também registrada mais tarde, em 1546, às vésperas do cerco de Diu. Em carta ao vice-rei D. João de Castro, Henrique de Sousa Chichorro escrevia em 15 de maio daquele ano que a fortaleza não dispunha de mais de 560 homens, sendo 343 casados e os demais solteiros. Mas salientava que o vice-rei não deveria se espantar "da gente ser tam pouca porque aqui pode se mal goardar e mais com ouvidor que não ha d'entrar no mar e buscar navio e diz me que lhe mande a casa os capitães e os mestres e pilotos pera lhe dar juramento que não levem ninguem" ${ }^{53} \mathrm{~A}$ artilharia também era com freqüência desviada para os navios, como se verifica pela proibição que a este respeito alerta o rei a Martim Affonso de Castro em carta de 6 de março de 1605 em que "se prohibe aos capitães das fortalezas o servirem-se da artilheria d'ellas em seus navios." ${ }^{4}$

$\mathrm{Na}$ fortaleza vivia-se à espera do assalto, no mar os riscos da calmaria. A falta de atividade física, conseqüência de uma navegação sem risco levava a um estado de tensão entre os que viajavam num navio. Um sobrevivente da nau São Paulo, que foi para a Índia em 1560, escreveu que

não se passava um dia sem que alguém fosse roubado ou ferido. Mesmo entre as pessoas corajosas houve querelas e alguns formavam bandos opostos que se odiavam mortalmente, de forma que o galeão estava repleto de pecadores. ${ }^{55}$

O jogo, principalmente as cartas, era uma das poucas, porém condenadas, atividades a bordo de que se ocupavam os homens, sendo também a causa de muitas desavenças. Contra ele lutavam os padres embarcados, preocupados em "ocupar bem o tempo à gente que na nau vem ociosa", 56 
aliando o convencimento às multas e castigos físicos aplicados contra os que jogassem por "desenfadamento, se fosse fidalgo pagaria vinte cruzados para a Misericórdia, e se fosse baixo seria açoitado ao pé do mastro". ${ }^{57}$ Ainda se batiam os religiosos contra outras práticas ilícitas a bordo, como a prostituição e a leitura de livros profanos.

O mesmo comportamento, que para driblar a monotonia gerava conflitos, se verificou na fortaleza. Num domingo, conta Lopo de Sousa, juntaram-se jovens portugueses e meninos escravos que havia na fortaleza e se desafiaram. Cada parte elegia um capitão e tinha um bandeira. Lutavam com paus e pedras como se a batalha fosse verdadeira. No domingo seguinte a luta se repetiu, com muitos feridos:

E assim o fizeram algumas vezes, sendo os portugueses sempre vencedores. E, pelo mal que se faziam, foi-lhes vedado que o não fizessem mais. Mas era já a cousa tão acesa entre eles que, não esperando que viessem os domingos, nem menos ser-lhes concedido, em qualquer parte que se topavam, poucos ou muitos acometiam-se tão devotamente e com tanto ódio, que nos púnhamos a os ver admirados de tal mistério. ${ }^{58}$

Mas é no momento em que a ordem se desfaz, durante o cerco ou o naufrágio, que estes dois espaços se assemelham de forma surpreendente. Os cercos vividos nas Índias, o equivalente em terra dos naufrágios, receberam atenção dos cronistas portugueses dos séculos XVI e XVII mas de forma muito diferente da que as desventuras no mar suscitaram. As narrativas de naufrágios conheceram muitas edições populares ainda no século XVI, sendo a História Trágico-maritima, organizada por Bernardo Gomes de Brito, editada em dois tomos em Lisboa nos anos 1735 e 1736, contendo 12 relatos e uma descrição. ${ }^{59}$ Assim como estes "incitam a colocar perguntas desconcertantes e, quem sabe, estratégicas, a um outro tempo histórico", ${ }^{60}$ o mesmo se pode concluir das narrativas de cercos militares.

Diferentes razões, no entanto, moviam os autores das narrativas de naufrágios e de cercos. No caso do primeiro, os textos funcionavam como ex-votos, cuja função era "agradecer à Virgem Madre de Deus o salvamento, guardando a memória daqueles fatos dolorosos que corriam o risco de serem esquecidos". ${ }^{61}$ Enquanto no caso dos cercos também se queria evitar o esquecimento, mas esperava-se com isso elevar o povo português ao relatar seus feitos gloriosos. Havia ainda as motivaçóes pedagó- 
gicas, os textos produzidos para pagar uma promessa ou como encomenda de algum familiar do náufrago. ${ }^{62} \mathrm{Na}$ segunda metade do século XVI, os folhetos que narram as infelicidades sofridas na Carreira da Índia tornaram-se mais numerosos, marcando o que posteriormente seria chamado de “ 'discurso narrativo do fracasso' (...) que reivindica o valor do infortúnio e o mérito do sofrimento". ${ }^{63}$ Madeira explica que o interesse por essas histórias trágicas, que colocam o leitor em contato com os acontecimentos reais, funciona como um contraponto aos discursos épicos e laudatórios sobre as façanhas expansionistas, comerciais e coloniais dos portugueses. ${ }^{64}$

$\mathrm{O}$ cerco militar e a cidade sitiada são temas recorrentes também na ficção. Para ficarmos apenas em exemplos recentes, podemos citar $A$ História do Cerco de Lisboa, de José Saramago, onde a libertação da cidade das mãos dos mouros caberia apenas aos portugueses, sem a ajuda dos cruzados; $A$ Ilha do Dia Anterior, de Umberto Eco, em que, após o naufrágio de um navio, o protagonista se salva em um barco abandonado e passa a rememorar um cerco vivido na juventude na cidade de Casale; e $O$ Deserto dos Tártaros, de Dino Buzzatti, a eterna vigília na fortaleza à espera de um ataque que traga honra e glória. A atração que o tema exerce entre os ficcionistas pela capacidade de exacerbar os sentimentos e levar a momentos-limite ajuda a explicar alguns elementos que justificam o uso das narrativas reais de cercos como fonte prodigiosa para o estudo de sociedades e mentalidades.

Comparativamente ao que pode ser considerado um gênero literário fruto da expansão ultramarina - as narrativas de naufrágio - as narrativas de cerco foram muito menos numerosas, mas nem por isso deixam de apresentar uma tipologia. Elas são um concentrado de informações sobre a disposição portuguesa diante do habitante da terra, inicialmente invadida, que passa a querer invadir o enclave português. Mas podemos destacar alguns elementos comuns: em primeiro lugar é descrito o contexto do conflito, em que se destacam a forma como foi construída a fortaleza e o início das rivalidades; em seguida trata-se do conflito, com incansáveis descrições de batalhas; e após o desfecho, normalmente feliz para os portugueses, apresenta-se uma relação dos homens e mulheres que se destacaram durante os combates e eram por isso dignos de mercês. Ao relatar o conflito propriamente, os autores sempre salientam a luta de poucos contra muitos; o Deus cristão que apóia a guerra contra o infiel; a morte com 
glória; a ação dos heróis fidalgos e homens do povo; a atitude corajosa das mulheres. Ao longo do relato encontra-se a percepção que os portugueses têm do inimigo e a que fazem de si mesmos.

Em apertados cercos e em naufrágios vive-se situações-limite - ou "ponto de desordem", ${ }^{65}$ como constata Madeira no caso do navio: o medo, a escassez de água, a fome, a vida em confinamento, a fúria dos soldados e do mar. Sente-se, então, o medo da morte e o desejo de salvar a alma. Diante da ameaça do mar, assiste-se a confissões públicas dos pecados, quando se espera obter a misericórdia divina. Durante o naufrágio da nau São Paulo, "cada um, a partir de então, desesperado da salvação de seu corpo, só pensava em salvar a alma e todos queriam se confessar aos religiosos que estavam no navio". ${ }^{66}$ Da mesma forma, na nau Conceição, que naufragou em 1555,

todos, grandes e pequenos, chamaram por Nossa Senhora, com uma grita que não nos ouvíamos uns aos outros, chorando e pedindo misericórdia a Nosso Senhor de nossos pecados, com vozes tão altas que parecia que se fundia o Céu, e todos tínhamos aquela pela derradeira hora de nossa vida ${ }^{67}$

Giovanni da Empoli descreve o naufrágio da nau Flor del Mare em 1512, e como, em seguida, com um pouco de biscoito e apenas uma ração de água por dia, feita a metade de água salgada, temendo perder a monção favorável para retornar a Goa, "eram tantos os tormentos e o murmúrio, olhar um o rosto do outro, (...) a fazer procissões e votos, que não havia santo no Paraíso que não se invocasse a cada dia” ${ }^{68}$

Em uma fortaleza cercada, diante da violência dos combates e da morte iminente, tentava-se também garantir a salvação eterna. $\mathrm{O}$ narrador do primeiro cerco de Diu descreveu o desespero no curso de um ataque especialmente sangrento em que os turcos

lançando-lhes infinitos zargunchos e artifícios de fogo e muitas pedras, e pelos de fora tanta quantidade de frechas e espingardadas (...) e com isto tão estranhas gritas e brados fazendo mui deiferentes sons que parecia que o mundo se transtornava. Mui amiúde desciam do muro e lugares da peleja muitos dos nossos feridos, suas faces cheias de sangue e pó, com melancolizados semblantes e atribulados espíritos (...). Uns pediam que lhes fosse mostrada a figura do nosso Redentor antes que expirassem; (...) desciam outros queimados e abrasados do terrível fogo da pólvora, nus com 
as carnes despedaçadas tão disformes, que houve irmão que fugiu de irmão cuidando ser fantasma. Era coisa mui piedosa ver como em gritos e desassossegos, correndo com muita agonia que os tristes padeciam, andavam a buscar alguma água para mitigar sua inflamada miséria. ${ }^{69}$

Foi o temor, segundo Lopo de Sousa, a causa mortis de João da Nova. Seu histórico não era de um homem covarde, mas veio a ser "tão cortado do medo e vencido dele" que percorria os locais da peleja exortando a todos que se entregassem aos turcos, enquanto havia tempo para sua misericórdia. Recusou a mezinha oferecida pelos físicos e "entregando-se tanto ao temor que veio a desfalecer (...) sem febre, sem dor, nem outro mal algum", ${ }^{70}$ acabou morrendo.

Esse narrador do primeiro cerco de Diu não mencionou confissões coletivas e em nenhum momento citou a presença de padres na fortaleza. Sabe-se que havia uma igreja, que mal acabou de ser construída foi destruída pelos turcos. Tendo em vista que a fortaleza já estava pronta havia dois anos, é difícil acreditar que ainda não houvesse um padre encarregado. No cerco de 1546 a Diu, fala-se de um clérigo que, com um crucifixo nas mãos, acompanhou o capitão da fortaleza na exortação aos sobreviventes do ataque ao baluarte da Rama. ${ }^{71}$

Já para o ano de 1565 tem-se um registro seguro. O Regimento para a fortaleza e cidade de Diu fala dos rendimentos previstos para o vigário e também o Orçamento da Índia, de 1571 , prevê $32 \$ 200$ réis por ano ao vigário. ${ }^{72}$ Em 1574, no entanto, o relatório da missão jesuíta no Oriente, escrita pelo Padre Jorge de Castro, afirma que nesta cidade, no reino de Cambaia, várias pessoas vinham pedir o batismo, "ainda que não haja padres e pessoas que particularmente se dediquem à conversão". ${ }^{73}$

No cerco imposto a Chaul em 1593, as confissões ocorriam também numerosas antes de cada combate. Na carta ânua, Francisco Cabral escrevia que, por causa do cerco que já durava sete meses:

Aconteceo muitas veses asentarem-sse os Padres à noite nos confissionarios e não se alevantarem delles senão às sinco horas da menhã. Em todos os asaltos de importancia vai algum dos nossos na dianteira com hum crucifixo, pera dar animo aos soldados, e outras pera confessarem os feridos e os ajudarem a recolher. ${ }^{74}$ 
Para preparar a alma antes da batalha também em Diu, após a chegada de D. João de Castro e antes do ataque que livraria a fortaleza, o vice-rei ouviu missa com todos os capitães e soldados. ${ }^{75}$ Morrendo no ataque, no entanto, estariam salvos, já que "morrer não era mais que hu breve espaço, que não tinhão mayor mal que não saber hu homem o que Deus delle esperava de fazer, por seos peccados, porque segundo a nossa fee sabião sua certa e be aventurança”. ${ }^{76}$ Foi também com essa esperança que, às vésperas do ataque do rei de Achém à Malaca, em 1574, o capitão Tristão Vaz da Veiga, ordenou "as coisas de sua alma, confessando-se e comungando e dispondo o mais que para aquele transe lhe pareceu necessário". ${ }^{77}$

Aliado ao desejo de salvar a alma atribuía-se à justiça divina as vitórias contra o infiel. O jesuíta Francisco Rodrigues, presente ao segundo cerco de Diu, em 1546, atribuiu a um milagre que "menos de 3.000 matarom grande multidão" ${ }^{78}$ milagre este partilhado pelos mouros, que "vião huma molher que os cegava e não deixava ter o rosto direito aos portugueses" ${ }^{79}$ Procissões deveriam ser feitas e o milagre pregado nos púlpitos, segundo o narrador, "porque verdadeiramente neste dia hia todo o negocio da India". ${ }^{80}$

A imagem síntese desses dois produtos e instrumentos da expansão é a Figura de Lisboa, de Francisco de Holanda. A ilustração integra a obra Da fabrica que falece à cidade de Lysboa, escrita em 1571 e dedicada a D. Sebastião, na qual o autor, depois de ter vivido na Itália, apresenta propostas de obras a serem feitas em Lisboa, no campo das fortificaçóes, do arruamento e do abastecimento de água. Nesta figura, vê-se uma mulher que emerge das águas do Tejo, segura uma nau nos braços e tem sobre a cabeça uma coroa na forma de uma muralha. Dois corvos, um sobre o ombro da mulher, outro sobre a nau, remetem àqueles que escoltaram a pequena embarcação que levou o corpo de São Vicente a Lisboa, conforme diz a lenda.

Assim como na imagem de Holanda estão presentes os veículos das ações portuguesas dignas de memória, outros gêneros literários apoiaramse na fortaleza e no navio, nos cercos e nos naufrágios para registrar esses feitos. No século XVI, Camões e Os Lusíadas, e outros poemas épicos tiveram o mesmo objeto: O primeiro cerco que os turcos puserão ha fortaleza de Diu nas partes da India, de autoria de Francisco de Andrade, publicado em 1589 e baseado no relato do cerco de Lopo de Sousa Coutinho. Mesmo em terra, recorre-se ao mar. No lugar das musas, o autor pede a Deus 
inspiração para escrever o poema: "Socorre eterno senhor supremo, / Porque eu em mar tam largo desatino / Ond'hu naufragio certo espero \& temo / Se me faltar o teu favor divino". (Canto I, estrofe 2). Há um poema do segundo cerco, de 1546, de Jerônimo Corte Real: Sucesso do Segundo Cerco de Diu. Estando Dom Joham Mazcarenhas por capitam da fortaleza, de 1574. Corte Real escreveu também um poema com base num naufrágio, cujo relato foi publicado por Bernardo Gomes de Brito: Naufrágio e Lastimoso Sucesso da Perdição de Manuel de Sousa Sepúlveda e Dona Leonor De Sá Sua Mulher, impresso em 1594.

$\mathrm{Na}$ fala dos religiosos, nos sermões, a mesma experiência

Onde estão, Senhor, aquelles, que no cerco de Malaca se lavantavam doentes de febres a pelejar, e no fervor da peleja saravam? Onde aquelles leões encerrados de Chaul? Onde aquelles encantados de Diu? Onde está aquelle, que do alto de hua gávea de um galeão rendido, se defendia dous dias de hua armada inteira? (...) Pois, Senhor, naquella Chaga de pé direito, que grilhões vejo tam pezados, hum nas conquistas da terra, outro nas navegaçôes do mar, impedidas huas, e outras pollo Herege, e pollo Mouro, que senhoreão o mar co armadas, \& occupão a terra com fortalezas! ${ }^{81}$

Bastante mais tarde, na nova fronteira do Império, no extremo oeste do Estado do Brasil, verifica-se a permanência das imagens gêmeas. Em Cuiabá, na Província do Mato Grosso, em 1794, durante as comemorações do nascimento da Princesa da Beira, os comerciantes da vila se ofereceram para mandar fabricar dois navios de madeira e representar duas óperas. Não tendo sido possível aprontar os dois navios, fizeram apenas um e substituíram o outro por uma fortaleza.

estando o povo junto da dita praça (na Vila Real do Senhor do Bom Jesus do Cuiabá), pelas quatro horas entrou por ela aquela esperada embarcação armada em guerra com todos os preparativos próprios, cuja entrada lhe foi disputada pela fortaleza, disparando-lhe muitos tiros de peça. ${ }^{82}$

Mesmo não sendo uma forma muito freqüente de analisar o papel desempenhado pelas fortalezas, a historiografia destaca o isolamento ao qual os portugueses estavam condenados com esta política. Como escreve Bo- 
xer, "os portugueses, como os holandeses e ingleses, tiveram de ficar nos seus fortes, trocando tigelas de latão, pulseiras, contas, têxteis... por ouro, marfim e escravos, trazidos do interior por comerciantes africanos itinerantes". ${ }^{83}$ Ballong-Wen-Mewuda vê São Jorge da Mina "completamente aprisionada, de ambos os lados, pelos reinos circundantes", ${ }^{84}$ assim como a praça de Mazagão, que a transferência para a Amazônia no século XVIII tornou célebre. Já no século anterior "estava reduzida a viver para si própria e de si própria, como em vaso fechado, isolada de um Berberia que a rodeava por todos os lados" ${ }^{85}$

Pode-se dizer, no entanto, que, no caso da Índia, o isolamento atingia o Estado português e não os portugueses propriamente. Ou seja, as restriçōes, quando não proibições, ao comércio privado não puderam evitar que, de um lado, o monopólio do comércio idealizado pela Coroa fosse minado, e que, de outro, renegados, mercenários e comerciantes se espalhassem por portos e cidades indianas onde o controle oficial, este sim, se restringia ao espaço da fortaleza.

$\mathrm{Na}$ fortaleza e no navio, esses dois espaços privilegiados da expansão, os portugueses entraram em contato e estabeleceram relações mais ou menos conflituosas com um grande número de outros agentes que representavam tantos outros interesses. $\mathrm{O}$ estudo do caráter cosmopolita das tripulações dos navios da Carreira da Índia, assim como da convivência igualmente forçada no interior da fortaleza, revela que as tensões acumuladas nestes encontros se revestiram de características peculiares, ligadas - há ainda muito o que insistir nesse sentido - à circulação por espaços de reclusão.

Foram numerosos os cercos sofridos pelos portugueses na Índia e serviram tanto de ilustração para a superioridade bélica dos portugueses como de desfecho para a perda de muitas praças. Ao estudar essas situaçôes-limite, para além do uso tradicional de exaltação dos feitos portugueses no ultramar, nos deparamos com uma organização muito semelhante à do navio. Esses dois espaços podem apontar uma tipologia do comportamento dos homens diante da reclusão. A análise das narrativas de cercos militares, um gênero típico da expansão produzido, porém, em número mais tímido do que os textos que relatam os naufrágios, demonstram em situaçôes extremas o cerco virtual vivido durante toda a permanência dos portugueses na Ásia. 


\section{Notas}

${ }^{1}$ A respeito dessa exigência de Cabral, ver FRADE, Alexandra. Os escrivães da armada de Pedro Álvares Cabral. In: COSTA, João Paulo Oliveira e (org.). Descobridores do Brasil. Lisboa: Sociedade Histórica da Independência de Portugal, 2000, p. 423. Destaca-se também a bonita imagem de Luís Filipe Thomaz ao tratar de D. Francisco de Almeida, "um vice-rei flutuante, governador de um Estado sem território, com o convés da sua nau por capital”. De Ceuta a Timor. Lisboa: Difel, 1994, p. 213.

${ }^{2}$ Ver HOLANDA, Sérgio Buarque de. Raízes de Brasil. 10a edição. Rio de Janeiro: José Olympio, 1986, p. 70-71.

${ }^{3}$ ARAÚJO, Julieta M. A. de Almeida; SANTOS, Ernesto J. Oliveira dos. Os portugueses e o reino no Congo. Primeiros Contatos. In: Missionação Portuguesa e Encontro de Culturas. vol. 1. Universidade Católica/ CNCDP, Braga, 1993, p. 642. Grifo nosso.

${ }^{4}$ PEARSON, M.N. Os portugueses na Índia. Lisboa: Teorema, 1990, p. 24.

${ }^{5}$ Idem, p. 50.

${ }^{6}$ CHÁ MASSER, Lunardo de. Relação de Lunardo Cha Masser. Apêndice a PERAGALLO, Prospero (ed.). Carta de El-Rei D. Manuel ao Rei Catholico. Lisboa: Academia Real de Sciências, 1892, p. 84.

${ }^{7}$ ALBUQUERQUE, Afonso de. Cartas para el-Rei D. Manuel I. Selecção, prefácio e notas de António Baião. Lisboa: Livraria Sá da Costa Editora, 1942. Carta de $1^{\circ}$ de dezembro de 1513, p. 126.

${ }^{8}$ A expressão é de Teotónio de Souza. Goa medieval. Lisboa: Teorema, 1993, p. 171.

${ }^{9}$ Apud RUSSELL-WOOD, A.J.R. Fronteiras de integração. In: BETHENCOURT, Francisco; CHAUDHURI, Kirti (dir.). História da Expansão Portuguesa, vol. I. Lisboa: Círculo de Leitores, 1998, p. 250.

10 "Regimento de Tomé de Sousa". Apud HOLANDA, Sérgio Buarque de. Raízes de Brasil, p. 66.

${ }^{11}$ Ver HOLANDA, Sérgio Buarque. Raízes de Brasil, p. 70.

${ }^{12}$ Idem, p. 71.

${ }^{13}$ Idem, p. 73.

${ }^{14}$ Idem, p. $74 \mathrm{~s}$.

${ }^{15}$ CORSALI, Andrea. Due lettere dall'India di Andrea Corsali. In: RAMUSIO, Giovanni Battista. Navigazioni e Viaggi. Vol. II. Torino: Giulio Einaudi editore, 1979, p. 37.

${ }^{16}$ COUTINHO, Lopo de Sousa. Livro primeiro do cerco que os turcos poseram a fortaleza de Diu. In: MACHADO, Diogo Barbosa (collegida por). Notícia dos cercos heroicamente sustentados pelos portuguezes nas quatro partes do mundo, Tomo 1. Coimbra: por João Alvarez, imprimidor da Universidade, 1561, Livro I, cap. 3.

${ }^{17}$ Carta a Bernardo Davanzati. Cochim, 22.01.1586. In: SASSETTI, Filippo. Lettere dall'India (1583-1588). A cura di Adele Dei. Roma: Salerno Editrice, 1995, p. 165. O autor escreve "scopaliti", que traduzo aqui por "varre-praia". 
${ }^{18}$ Ver PINTO, João Rocha. A Viagem: Memória e Espaço. Lisboa. Cadernos da Revista de História Económica e Social, 11-12, Livraria Sá da Costa Editora, 1989, p. 85s.

${ }^{19}$ PICCHIO, Luciana Stegagno. A literatura de viagens e o diálogo italo-português. Postilas a um colóquio. In: Mare liberum, no 2, Lisboa, 1991, p. 95.

${ }^{20}$ Ver BARRETO, Anibal. Fortificações do Brasil. Rio de Janeiro: Biblioteca do Exército, 1958 , p. $165-173$.

${ }^{21}$ CORREIA, Gaspar. Lendas da Índia. Porto: Lello \& Irmãos Editores, 1975, I-527.

${ }^{22}$ Cf. Idem, I - 529s.

${ }^{23}$ Apud SUBRAHMANYAM, Sanjay. O Império Asiático Português. Lisboa: Difel, 1995, p. 91.

${ }^{24}$ Carta de D. Manuel a D. Francisco de Almeida, 1506. ApudTHOMAZ, Luís Filipe. L'Idée impériale manuéline. In: AUBIN, Jean (éd.). La Découverte, le Portugal e l'Europe - Actes du colloque. Fondation Calouste Gulbenkian - Centre Culturel Portugais, 1990, p. 41. Uma edição em português deste artigo está publicado em DORÉ, Andréa; LIMA, Luis Filipe Silvério; SILVA, Luiz Geraldo (orgs.). Facetas do Império na História: conceitos e métodos. São Paulo: Hucitec, 2008.

${ }^{25}$ Relação de Lunardo Cha Masser, p. 85.

26 SUBRAHMANYAM, S., op. cit., p. 96.

${ }^{27}$ Mário Pereira prefere considerar que na Idade Moderna assistiu-se à passagem da "'arte' de defender à ciência da fortificação", englobando como principal aspecto o avanço da pirobalística sobre a neurobalística e a conseqüente substituição da torre pelo baluarte. "Da torre ao baluarte." In: A arquitectura militar na expansão portuguesa. Lisboa: CNCDP, 1994, p. 38.

${ }^{28}$ A respeito da participação dos arquitetos italianos na elaboração dos projetos e na construção das fortalezas portuguesas, ver MOREIRA, Rafael. "A arte da guerra no Renascimento". In: MOREIRA, Rafael (direcção de). História das fortificaçôes portuguesas no mundo. Lisboa: Alfa, 1989, p. 143-158. Sobre o primeiro desses mestres, ver John B. Bury. Benedetto da Ravenna (c.1485-1556). In: A arquitectura militar na expansão portuguesa, p. 130-134.

${ }^{29} \mathrm{O}$ padre Fernando Oliveira e a sua obra náutica. In: Memória da Academia Real das Ciências de Lisboa. Lisboa, 1898.

${ }^{30} \mathrm{O}$ manuscrito autógrafo da 'Ars nautica' de Fernando Oliveira. In: Boletim Internacional de Bibliografia Luso-Brasileira. Vol. I, no 2, Lisboa, 1960.

${ }^{31}$ Ver LENTI, Roberto. L'architettura navale portoghese all'inizio dell'età moderna. In: Studi in onore di Luigi Bulferetti. Miscellanea Storica ligure. Anno XVIII, no 1, vol. 1. Genova, 1968 , p. 216-219

32 MENDONÇA, H.L. de. O padre Fernando Oliveira e a sua obra náutica. Apud. LENTI, op. cit., p. 266.

${ }^{33}$ Ver DAGEN, Mathias. L'Architecture militaire moderne ou Fortification. Amsterdan: Louys Elzevier, 1648, p. 8. 
${ }^{34}$ Ver LENTI, Roberto, op. cit. p. 228.

${ }^{35}$ Ver NUNES, António Lopes Pires. O castelo estratégico português e a estratégia do castelo em Portugal. Lisboa: Direcção do Serviço Histórico Militar, 1988, p. 72.

${ }^{36}$ Ver Idem, p. 73. Os merlóes são a parte maciça do parapeito que fica entre duas canhoeiras, no alto dos baluartes ou das muralhas.

${ }^{37}$ MOREIRA, Rafael. Caravelas e baluartes. In: Arquitetura militar na expansāo portuguesa, p. 85.

${ }^{38}$ Idem, p. 85-87.

${ }^{39}$ Ver MOREIRA, Rafael. Cultura material e visual. In: História da expansão portugue$s a$, vol I, p. 465.

${ }^{40}$ GOFFMAN, Erving. Manicômios, prisões e conventos. 6a edição. São Paulo: Perspectiva, 1999, p. 11.

${ }^{41}$ MADEIRA, Maria Angélica. Notícias sobre a história trágico-marítima. In: Lugar comum, no 7, janeiro-abril 1999, p. 96.

42 ANDRADE, Amélia Aguiar. Novos espaços, antigas estratégias: o enquadramento dos espaços orientais. In: Os espaços de um Império. Estudos. Lisboa: CNCDP, 1999, p. 36.

${ }^{43}$ Ver Carta régia a D. Jerônimo de Azevedo. 06.03.1616. In: Documentos remettidos da Índia ou Livro das Monções (Direção de Raymundo Antonio Bulhão Pato). Lisboa: Typographia da Academia Real das Sciencias, 1884, III-440.

${ }^{44}$ A respeito das denúncias de corrupção, ver uma síntese em WINIUS, George Davidson. A lenda negra da Índia Portuguesa. Contributo para o estudo da corrupção política nos impérios do início da Europa moderna. Lisboa: Antígona, 1994

${ }^{45}$ Ver MADEIRA, M. Angélica. Relaçōes de poder em naus mercantes. In: Série Sociológica no 104. Brasília, 1993, p. 10.

${ }^{46}$ A bibliografia a respeito da vida à bordo das naus durante a expansão portuguesa é abundante. Para citar alguns trabalhos entre os mais significativos: MICELI, Paulo. $O$ ponto onde estamos. Viagens e viajantes na História da Expansão e da Conquista. $3^{\mathrm{a}} \mathrm{ed}$. Campinas: Editora da Unicamp, 1998, p. 135-160; GRACIAS, M. Fátima da Silva. Entre partir e chegar: saúde, higiene e alimentação a bordo da Carreira da Índia no século XVIII, p. 457-468 e GUERREIRO, Inácio. A vida a bordo na Carreira da Índia. A torna-viagem, p. 415-432, ambos em A carreira da India e a rota dos estreitos. - Actas do VIII Seminário Internacional de História Indo-Portuguesa. Angra do Heroísmo, 1998; RUSSELL-WOOD, A.J.R. Seamen Ashore and afloat: the social environment in the Carreira da Índia, 1550-1750. In: The Mariner's Mirror, vol. 69, no 1 . London, feb, 1983, p. 35-52.

${ }^{47}$ Os negros nos navios davam à bomba, podiam ser remeiros na galés, colaboravam na aguada e na luta contra os inimigos. A única função de relevo era, no entanto, a turgimania, ou seja, a atividade de intérprete. Ver NUNES, Aida. Os africanos - o quotidiano dos negros à bordo das caravelas. In: Descobridores do Brasil, p. 439-446.

${ }^{48}$ Ver MADEIRA, M. Angélica, op. cit., p. 11. 
49 SCAMMELL, Geoffrey. Seafaring in the Estado da Índia c. 1500-1700. In: Mare liberum, no 9, 1995, p. 444. A citação está em CARLETTI, Francesco. My voyage around the world. Ed. and trans. Herbert Weinstock. London, 1965, p. 185s.

${ }^{50}$ Carta a Pier Vettori. Cochin, 27.01.1585. In: SASSETTI, Filippo. In: Lettere dall'India (1583-1588), p. 76.

${ }^{51}$ MOREIRA, Rafael; CURVELO, Alexandra. A circulação das formas. Artes portáteis, arquitetura e urbanismo. In: História da expansão portuguesa, II-561s.

52 ALBUQUERQUE, Afonso de. Cartas para el-Rei D. Manuel I, p. 20.

${ }^{53}$ Colecção de São Lourenço. Prefácio e notas de Elaine Sanceau. Lisboa: Centro de Estudos Históricos Ultramarinos da Junta de Investigações Científicas do Ultramar, 1975, vol. I, p. 268s.

${ }^{54}$ Carta régia a Dom Martim Affonso de Castro. 6 de março de 1605. Documento 7. Documentos remettidos da Índia ou Livro das Monçōes, I-29-32. Ver também Carta régia ao secretário do Estado da Índia Francisco de Sousa Falcão, 08.02.1602. In: Idem, III512 e Carta régia ao vice-rei D. Jeronymo de Azevedo, 26.01.1612. In: Idem, II-142.

${ }^{55}$ LANCIANI, Giulia. Une histoire tragico-maritime. In: Lisbonne hors les murs. Paris: Editions Chandeigne, 1990, p. 97.

56 Padre Antônio de Quadros, 18.12.1555. In: WICKI, Joseph. Documenta Indica (1553-1557), vol. 3, p. 391. Apud. Paulo Miceli, op. cit, p. 152.

57 (Goa) Cochim, janeiro de 1562. In: Documenta Indica (1561-1563), vol. 5, p. 490. Apud. MICELI, op. cit, p. 153. Também sobre o jogo a bordo, ver GUERREIRO, op. cit., p. 427-429.

${ }^{58}$ COUTINHO, Lopo de Sousa, Livro II, cap. I, p. 84s.

${ }^{59}$ Em 1998, foi editada pela primeira vez no Brasil pela Lacerda Editores, do Rio de Janeiro.

${ }^{60}$ MADEIRA, Maria Angélica. 'Relato de naufrágio': um artefato cultural. In: VI Colóquio UERJ. Interseções: a materialidade da comunicação. Rio de Janeiro, 1998, p. 304.

${ }^{61}$ Idem, p. 309.

${ }^{62}$ Ver MADEIRA, Maria Angélica. Notícias sobre a história trágico-marítima, p. 93.

${ }^{63}$ MADEIRA, Maria Angélica. 'Relato de naufrágio': um artefato cultural, p. 305s.

${ }^{64}$ Ver MADEIRA, Maria Angélica. Notícias sobre a história trágico-marítima, p. 94.

${ }^{65}$ Idem, p. 98. O termo "situação-limite" também é utilizado pela autora em um outro artigo: "A percepção do tempo como 'situação-limite' - a vida como naufrágio e a condição do sujeito como náufrago, sobrevivente - parece-me metáfora suficientemente forte para fazer um texto extemporâneo falar de dentro do tempo presente." Intertextualidade e transdisciplinaridade: problemas de método. In: Language and literature today. Vol. II. Anais do XIX Congresso da Federação Internacional de Língua e Literatura Moderna, Brasília, 1996, p. 993.

${ }^{66}$ LANCIANI, Giulia, op. cit., p. 98. 
${ }^{67}$ RANGEL, Manuel. Relação do naufrágio da nau Conceição de que era capitão Francisco Nobre, a qual se perdeu nos baixos de Pêro dos Banhos aos 22 dias do mês de agosto de 1555. In: BRITO, Bernardo Gomes de. História trágico-maritima. Rio de Janeiro: Lacerda Editores/Contraponto, 1998, p. 99. Sobre as manifestaçôes religiosas nos navios da Carreira, ver LOPES, Maria de Jesus dos Mártires. Devoções e invocações à bordo da Carreira da Índia (séculos XVI-XVIII). In: A carreira da India e a rota dos estreitos, p. 433-444.

${ }^{68}$ SPALLANZANI, Marco. Giovanni da Empoli. Mercante navigatore fiorentino. Firenze: SPES, 1984, p. 166.

${ }^{69}$ COUTINHO, Lopo de Sousa, Livro II, cap. 18, p. 195.

${ }^{70}$ Idem, Livro II, cap. 14, p. 166.

${ }^{71}$ BAIÃO, António (ed.). História quinhentista (inédita) do segundo cerco de Dio. Coimbra: Imprensa da Universidade, 1927, p. 63.

72 O Orçamento do Estado da Índia 1571. Direcção e prefácio de Artur Teodoro de Matos. Lisboa: CNCDP, 1999, p. 32.

73 WICKI, Joseph. Documenta Indica, Vol. VIII, p. 742.

${ }^{74}$ Doc. 53 Goa, 15 novembro, 1593. In: Op. cit., vol. XVI, p. 327.

${ }^{75}$ BAIÃO, António (ed.), op. cit., p. 86.

${ }^{76}$ Idem, p. 63. O narrador Leonardo Nunes atribui essas palavras ao capitão da fortaleza D. João Mascarenhas ao exortar seus soldados.

77 LEMOS, Jorge de. Descrição dos cercos de Malaca, sendo capitão Tristão Vaz da Veiga. In: Textos sobre o Estado da Índia. Lisboa: Alfa, 1989, Primeira Parte, cap. VIII, p. 89.

${ }^{78}$ Carta de Cochim a 8 de dezembro de 1547. Documenta Indica, vol. I, p. 230.

${ }^{79}$ Carta de 16 de dezembro de 1546. In: Op. cit.

${ }^{80} \mathrm{Idem}$.

${ }^{81}$ P. Francisco de Macedo. Sermão (...) na festa de S. Thomé (...), fls. 12-12v. apud MARQUES, João Francisco. A Parenética portuguesa e a dominação filipina. Porto: Instituto Nacional de Investigação Científica, Centro de História da Universidade do Porto, 1986 , p. $270-71$.

${ }^{82}$ SEQUEIRA, Joaquim da Costa. Compendio Histórico Chronologico das Notícias do Cuyabá. Repartição da Capitania de Mato-Grosso. Revista do Instituto Histórico e Geográfico Brasileiro, 2a . Série, t. VI, Rio de Janeiro, p. 29, citado por MOURA, Carlos Francisco. Teatro a bordo de naus portuguesas nos séculos XV, XVI, XVII e XVIII. Rio de Janeiro, Instituto Luso-Brasileiro de História / Liceu Literário Português, 2000, p. $21 \mathrm{~s}$.

83 BOXER, Charles. O Império colonial português (1415-1825). Lisboa: Edições 70, 1972 , p. 54.

${ }^{84}$ BALLONG-WEN-MEWUDA, J. Bato'Ora. A fortaleza de São Jorge da Mina. Testemunho da presença portuguesa na costa do Golfo da Guiné do século XV ao século XVII. In: Revista Oceanos - Fortalezas da Expansão Portuguesa. no 28, Lisboa, out./nov. 1996, p. 30. 
${ }^{85}$ RICARD, Robert. Un document portugais sur la Place de Mazagan au debut du XVIIème siècle. Apud VIDAL, Laurent. Mazagão. A cidade que atravessou o Atlântico. Lisboa: Teorema, 2007, p. 22. O documento em questão é a transcrição para francês de uma descrição da fortaleza pelo governador Jorge de Mascarenhas (1615-2629).

\section{Referências bibliográficas}

ANDRADE, Amélia Aguiar. Novos espaços, antigas estratégias: o enquadramento dos espaços orientais. In: Os espaços de um Império. Estudos. Lisboa: CNCDP, 1999, p. 35-45.

BALLONG-WEN-MEWUDA, J. Bato'Ora. A fortaleza de São Jorge da Mina. Testemunho da presença portuguesa na costa do Golfo da Guiné do século XV ao século XVII. Revista Oceanos - Fortalezas da Expansão Portuguesa. no 28, Lisboa, out./nov. 1996, p. 27-39.

BARRETO, Aníbal. Fortificações do Brasil. Rio de Janeiro: Biblioteca do Exército, 1958.

BOXER, Charles. O Império colonial português (1415-1825). Lisboa: Edições $70,1972$.

COSTA, João Paulo Oliveira e (org.). Descobridores do Brasil. Lisboa: Sociedade Histórica da Independência de Portugal, 2000.

GOFFMAN, Erving. Manicômios, prisões e conventos. 6a edição. São Paulo: Perspctiva, 1999.

HOLANDA, Sérgio Buarque de. Raizes de Brasil. 10a edição. Rio de Janeiro: José Olympio, 1986.

LANCIANI, Giulia. Une histoire tragico-maritime. In: Lisbonne hors les murs. Paris: Editions Chandeigne, 1990, p. 89-116.

LENTI, Roberto. L'architettura navale portoghese all'inizio dell'età moderna. In: Studi in onore di Luigi Bulferetti. Miscellanea Storica ligure. Anno XVIII, no1, vol.1. Genova, 1968, p. 215-288.

Madeira, Angélica. Livro dos naufrágios. Ensaio sobre a História Trágico-Maritima. Brasília: Editora da UnB, 2005.

MADEIRA, Maria Angélica. 'Relato de naufrágio': um artefato cultural. VI Colóquio UERJ. Interseçôes: a materialidade da comunicação. Rio de Janeiro, 1998, p. 304-313.

MADEIRA, Maria Angélica. Intertextualidade e transdisciplinaridade: problemas de método. Language and literature today. Vol. II. Anais do XIX Congres- 
so da Federação Internacional de Língua e Literatura Moderna, Brasília, 1996, p. 987-994.

MADEIRA, Maria Angélica. Notícias sobre a história trágico-marítima. Lugar comum, no 7, janeiro-abril 1999, p. 93-102.

MICELI, Paulo. O ponto onde estamos. Viagens e viajantes na História da Expansão e da Conquista. 3a ed. Campinas: Editora da Unicamp, 1998.

MOREIRA, Rafael. A arte da guerra no Renascimento. In: MOREIRA, Rafael (direcção de). História das fortificações portuguesas no mundo. Lisboa: Alfa, 1989, p. 143-158.

MOREIRA, Rafael. Caravelas e baluartes. In: Arquitetura militar na expansão portuguesa. Lisboa: CNCDP, 1994, p. 83-89.

MOURA, Carlos Francisco. Teatro a bordo de naus portuguesas nos séculos XV, XVI, XVII e XVIII. Rio de Janeiro, Instituto Luso-Brasileiro de História / Liceu Literário Português, 2000.

NUNES, António Lopes Pires. O castelo estratégico português e a estratégia do castelo em Portugal. Lisboa: Direcção do Serviço Histórico Militar, 1988, p. 72.

PEARSON, M.N. Os portugueses na Índia. Lisboa: Teorema, 1990, p. 24.

PEREIRA, Mario. Da torre ao baluarte. In: A arquitectura militar na expansão portuguesa. Lisboa: CNCDP, 1994, p. 35-42.

PICCHIO, Luciana Stegagno. A literatura de viagens e o diálogo italo-português. Postilas a um colóquio. Mare liberum, no 2, Lisboa, 1991.

PINTO, João Rocha. A viagem: memória e espaço. Lisboa. Cadernos da Revista de História Económica e Social, 11-12, Livraria Sá da Costa Editora, 1989.

RUSSELL-WOOD, A.J.R. Fronteiras de integração. In: BETHENCOURT, Francisco; CHAUDHURI, Kirti (dir.). História da expansão portuguesa, vol. I. Lisboa: Círculo de Leitores, 1998.

RUSSELL-WOOD, A.J.R. Seamen Ashore and afloat: the social environment in the Carreira da Índia, 1550-1750. In: The mariner's mirror, vol. 69, ํㅜ1. Londres, fev., 1983, p. 35-52.

SCAMMELL, Geoffrey. Seafaring in the Estado da Índia c. 1500-1700. In: Mare liberum, no 9, 1995, p. 441-451.

SOUZA, Teotónio de. Goa medieval. Lisboa: Teorema, 1993.

SUBRAHMANYAM, Sanjay. O Império Asiático Português. Lisboa: Difel, 1995, p. 91.

THOMAZ, Luís Filipe F. R. De Ceuta a Timor. Lisboa: Difel, 1994. 
THOMAZ, Luís Filipe. A idéia imperial manuelina. In: DORÉ, Andréa; LIMA, Luis Filipe Silvério; SILVA, Luiz Geraldo (orgs.). Facetas do Império na História: conceitos e métodos. São Paulo: Hucitec, 2008.

VIDAL, Laurent. Mazagão. A cidade que atravessou o Atlântico. Lisboa: Teorema, 2007.

\section{RESUMO}

Este artigo pretende salientar algumas relaçôes que podem ser estabelecidas entre os dois principais veículos da expansão portuguesa: a fortaleza e o navio. Esses dois espaços de reclusão podem ser entendidos como "instituiçôes totais", na forma como as define Erving Goffman, e apresentam profundas semelhanças, principalmente quando se analisam momentos-limite vividos pelos individuos, durante os naufrágios e durante as situaçōes de cerco. Para este efeito privilegia-se a presença portuguesa no Oceano Índico, caracterizada pela construção de uma rede de fortalezas sem uma significativa penetração no território.

Palvaras-chave: expansão portuguesa, "instituiçôes totais", fortaleza, navio.

\section{ABSTRACT}

This article intends to point out some relations that can be established between two principal vehicles of the Portuguese expansion: the fortress and the ship. These two spaces of reclusion can be understood like "total institutions", in the form as Erwing Goffman defines them, and present deep similarities, principally when moments-limits survived by the individuals are analysed, during the shipwrecks and during the situations of siege. For this effect the Portuguese presence is privileged in the Indian Ocean, characterized by the construction of a net of fortresses without a significant penetration in the territory.

Keywords: Portuguese expansion, "total institutions", fortress, ship.

Recebido em março de 2007 e aprovado em setembro de 2007 